\title{
Scrutinize Research on Underwater Welding Process: A Review
}

\author{
Mayank Chandra Joshi, Deepak Singh Rautela, Rajat Chauhan, Sumit Suyal. \\ Tulas institute dhoolkhot dehradun.
}

\begin{abstract}
The paper describes principles of underwater welding and recent trends in research works undertaken for enhance welding technology and properties of underwater welds. Welding in offshore and marine application is an area of research and understanding where, many problems are still unsolved. In the present paper, a brief classification of underwater welding is made, the principals involved and the advantages and disadvantages of the various types of underwater welding are described.The paper discusses various topics including temperature histories and microstructural transformation, optimum welding current and speed, optimum weld bead shape, and optimum hardness profiles. The entire program covered various subjects including the heat transfer and flow during underwater welding, the mechanisms of metal transfer and arc bubble formation, and the effects of water environment on the metallurgical structures and the properties of underwater welds.
\end{abstract}

Keywords: underwaterwelding, microstructural transformation, metallurgical structure.

\section{Introduction}

Welding process can be defined as the metallurgically joining two pieces of metals by fusion to produce essentially a single piece of metal. welding technology is more then 2500 years old. with the advancements that have taken place in the welding technology,almost all metals are weldable provided that the proper process and technique are used. by using proper techniques,it is possible to weld even plastic and glasses.the welding process joins two pieces of metal by applying intense heat or pressure or both to melt the edges of the metal so that they fuse permanentally. the joint formed is a permanent joint. in welding, filler material may also be used. the heat required for the process of welding can be obtained by useing an electric arc, electric current, gas flame, or chemical reaction. the process of welding can be done with or without the application of pressure.

Underwater welding is an important tool for underwater fabrication works. In 1946, special waterproof electrodes were developed in Holland by 'Van der Willingen'. In recent years the number of offshore structures including oil drilling rigs, pipelines, platforms are being installed significantly. Some of these structures will experience failures of its elements during normal usage and during unpredicted occurrences like storms, collisions. Any repair method will require the use of underwater welding.

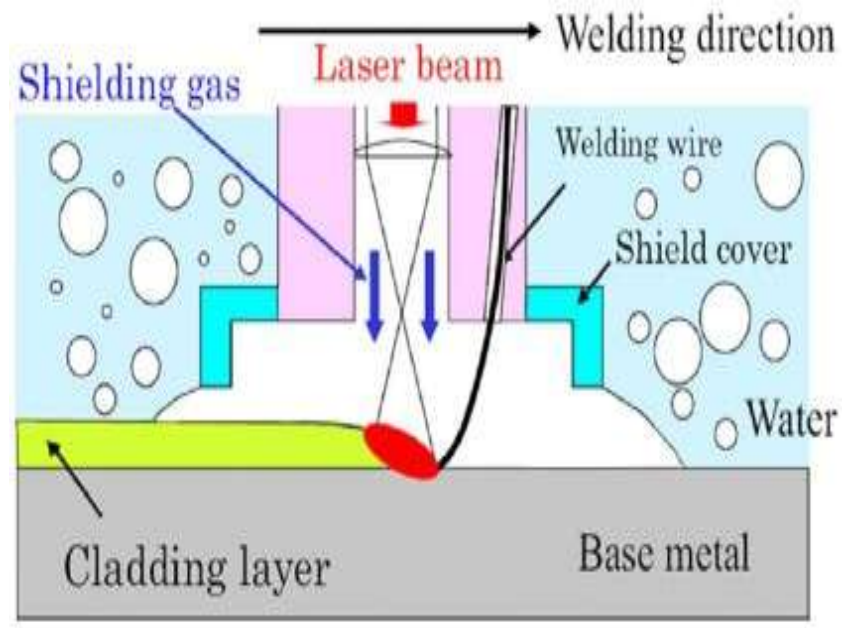

Fig-1.

Attempts to use underwater welding for the repair and salvage of ships and other ocean engineering structures have been marginally successful since the early part of this century.Most of the developments and improvements in underwater welding have come from trial and error investigations by those who actually needed a more satisfactory underwater weld. But beginning in the early 1960's and continuing to the present time, several workers have been studying the processes and phenomena of underwater welding on a more fundamental scientific and engineering basis. Several workers in Russia have reported on various aspects of both shielded metal-arc and thin wire (GMA) underwater welding processes. Although they have laid few theoretical 
foundations for the phenomena they have observed, their observations are many and precise.

\section{Overview}

Underwater welding is more difficult in comparison to that performed at open air because of: higher pressure, hydrogen content in weld metal and higher cooling rates. It has been proved that increased pressure makes welding arc unstable and the presence of diffusible hydrogen and brittle microstructures in the welds can be the reasons of cracks formation. In the most cases underwater welding is used for joining carbon steels, low alloy steels, austenitic and duplex stainless steels. Weldability of steel in water environment is governed by its cold or hot cracking tendency. Susceptibility to cold cracking is main problem in welding of high strength low alloy steels (HSLA) and fabrication of dissimilar joints. Hot cracks in the most cases are observed in weld metal of fully austenitic stainless steels.

\section{Types Of Underwater Welding.}

The classification of underwater welding techniques is presented in Fig

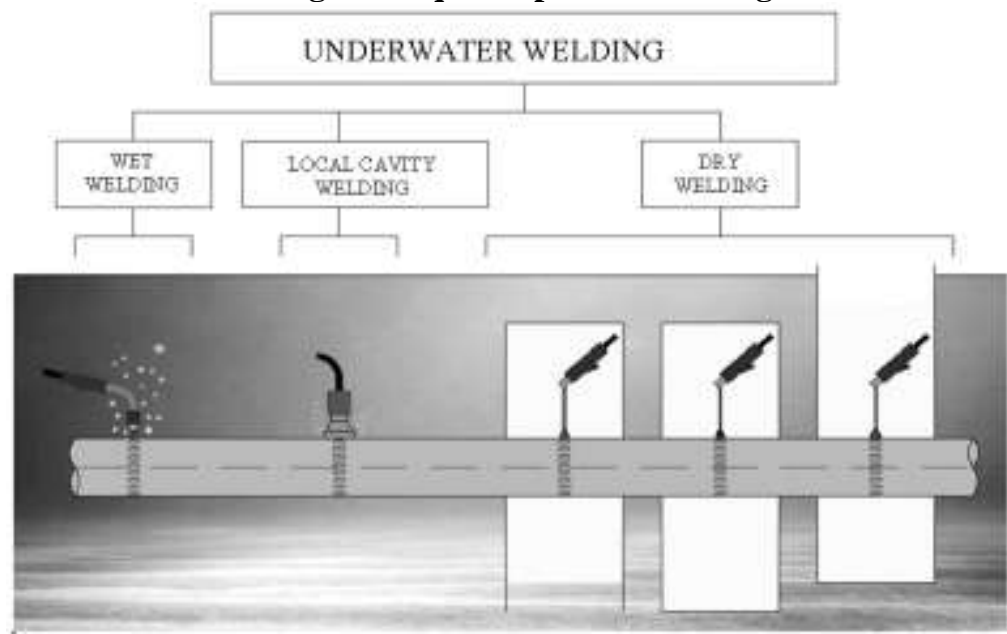

Fig-2.

In wet welding the welding is performed underwater, directly exposed to the wet environment. In dry welding, a dry chamber is created near the area to be welded and the welder does the job by staying inside the chamber.

\section{Wet Welding}

Wet Welding indicates that welding is performed underwater, directly exposed to the wet environment. A special electrode is used and welding is carried out manually just as one does in open air welding. The increased freedom of movement makes wet welding the most effective, efficient and economical method. Welding power supply is located on the surface with connection to the diver/welder via cables and hoses.

In wet welding MMA (manual metal arc welding) is used.

Power Supply used: DC

Polarity: -ve polarity

When DC is used with +ve polarity, electrolysis will take place and cause rapid deterioration of any metallic components in the electrode holder. For wet welding AC is not used on account of electrical safety and difficulty in maintaining an arc underwater.

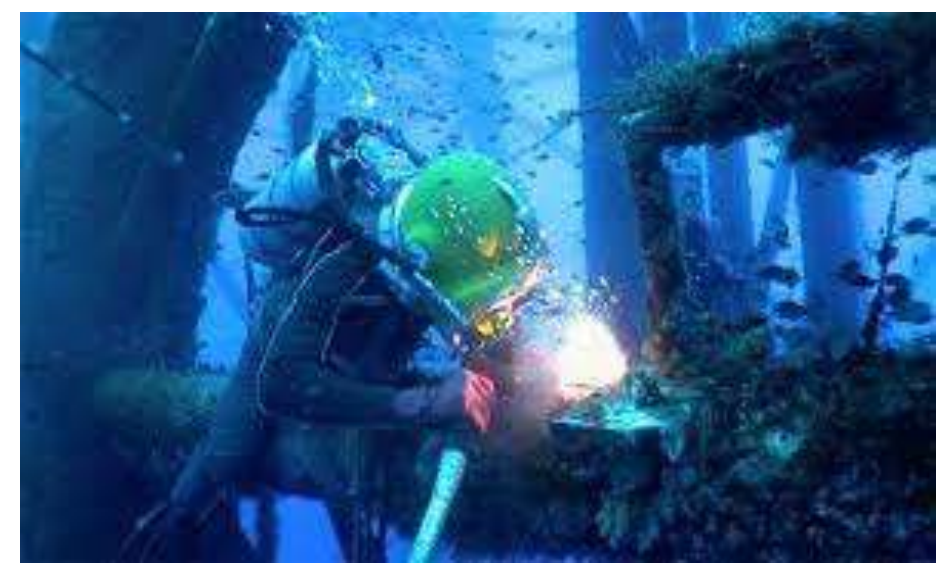


Fig-3.

The power source should be a direct current machine rated at 300 or 400 amperes. Motor generator welding machines are most often used for underwater welding in the wet. The welding machine frame must be grounded to the ship. The welding circuit must include a positive type of switch, usually a knife switch operated on the surface and commanded by the welder-diver. The knife switch in the electrode circuit must be capable of breaking the full welding current and is used for safety reasons. The welding power should be connected to the electrode holder only during welding.

\section{Hyperbaric Welding (Dry Welding).}

Hyperbaric welding is carried out in chamber sealed around the structure o be welded. The chamber is filled with a gas (commonly helium containing 0.5 bar of oxygen) at the prevailing pressure. The habitat is sealed onto the pipeline and filled with a breathable mixture of helium and oxygen, at or slightly above the ambient pressure at which the welding is to take place. This method produces high-quality weld joints that meet X-ray and code requirements. The gas tungsten arc welding process is employed for this process. The area under the floor of the Habitat is open to water. Thus the welding is done in the dry but at the hydrostatic pressure of the sea water surrounding the Habitat.Underwater welding in a dry environment is made possible by encompassing the area to be welded with a physical barrier (weld chamber) that excludes water. The weld chamber is designed and custom built to accommodate braces and other structural members whose centerlines may intersect at or near the area that is tobe welded. The chamber is usually built of steel, but plywood, rubberized canvas, or any other suitable material can be used.

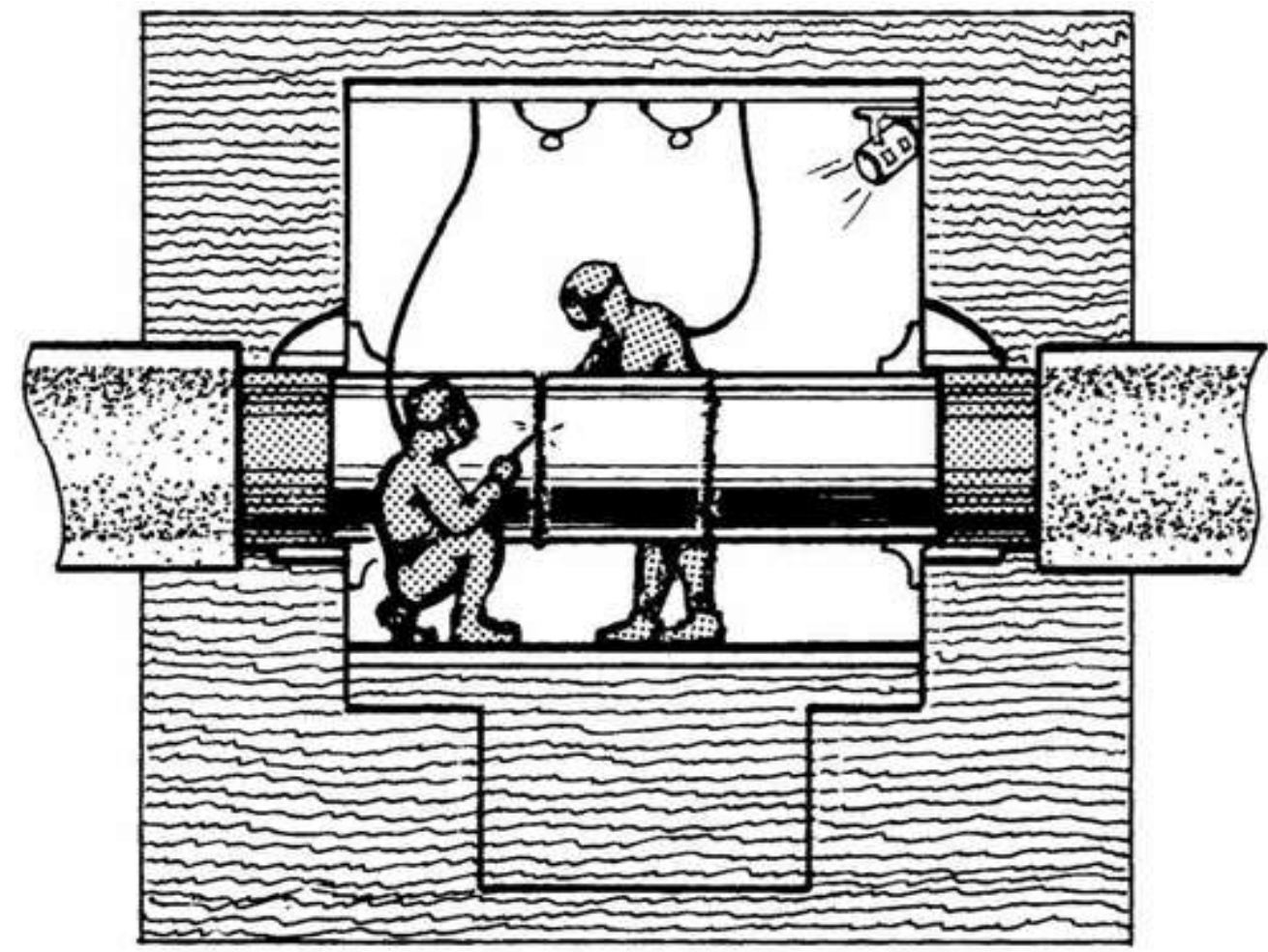

Underwater welding in dry conditions

Fig-4.

\section{Risk Involves}

There is a risk to the welder/diver of electric shock. Precautions include achieving adequate electrical insulation of the welding equipment, shutting off the electricity supply immediately the arc is extinguished, and limiting the open-circuit voltage of MMA (SMA) welding sets. Secondly, hydrogen and oxygen are produced by the arc in wet welding. Precautions must be taken to avoid the build-up of pockets of gas, which are potentially explosive. The other main area of risk is to the life or health of the welder/diver from nitrogen introduced into the blood steam during exposure to air at increased pressure. Precautions include the provision of an emergency air or gas supply, stand-by divers, and decompression chambers to avoid nitrogen narcosis following rapid surfacing after saturation diving. For the structures being welded by wet underwater welding, inspection following welding may be more difficult than for welds deposited in air. Assuring the integrity of such underwater welds may be more difficult, and there is a risk that defects may remain undetected. 


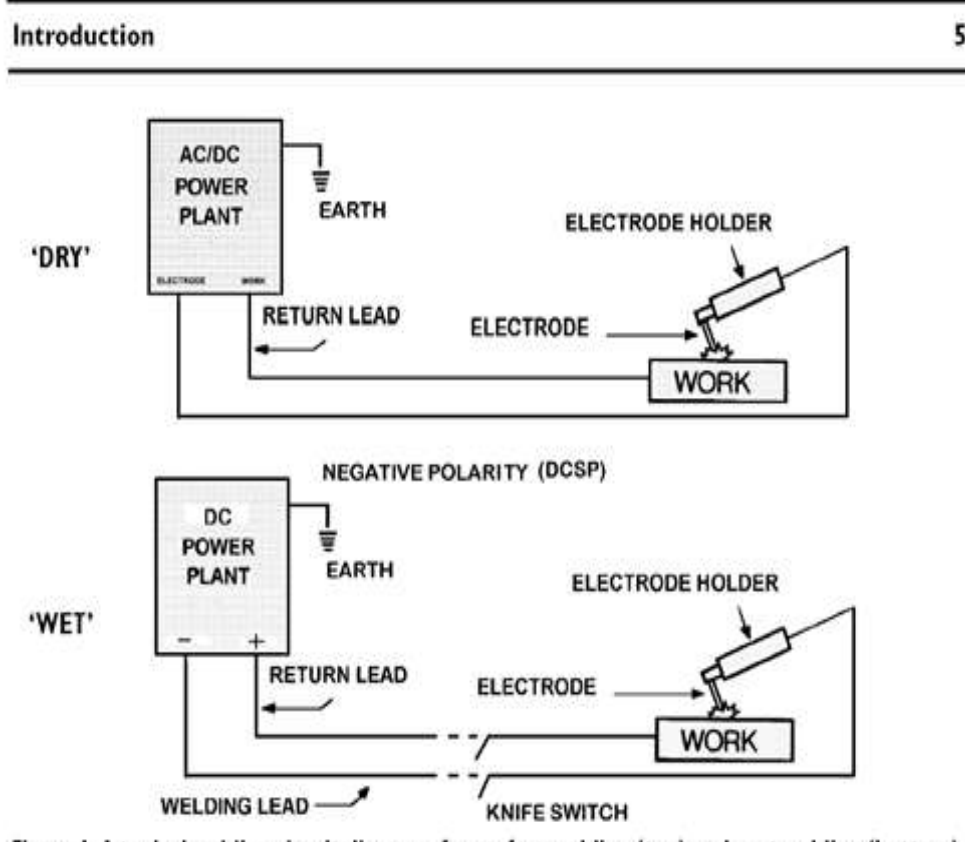

Figure I A typical welding circuit diagram, for surface welding (top) and wet welding (bottom).

Fig-5.

\section{Underwater Welding: Future Scope Of Development.}

Wet MMA is still being used for underwater repairs, but the quality of wet welds is poor and is prone to hydrogen cracking. Dry Hyperbaric welds are better in quality than wet welds. Present trend is towards automation. THOR - 1 (TIG Hyperbaric Orbital Robot) is developed where diver performs pipefitting, installs the trac and orbital head on the pipe and the rest process is automated.Developments of driverless Hyperbaric welding system is an even greater challenge calling for annexed developments like pipe preparation and aligning, automatic electrode and wire reel changing functions, using a robot arm installed. This is in testing stage in deep waters. Explosive and friction welding are also to be tested in deep waters.

Considerable research effort has been made to improve process performance and control strategies for the various underwater welding processes over the last half century. However, there are still many problems to overcome. The major efforts on research and development should be focused on the following topics:

a) Automation of the underwater joining and inspection of the welded structures.

b) Mechanized underwater welding for actual usage of very large floating structures.

c) Investigation of the potential of using a robot manipulator for underwater ultrasonic testing of welds in joints of complex geometry.

d) Application of advanced welding technique, like friction, laser welding and understand the behavior of materials after the welding and process optimization.

\section{Weldability of Steel In Water Environment}

Underwater welding is more difficult in comparison to that performed at open air because of: higher pressure, hydrogen content in weld metal and higher cooling rates. It has been proved that increased pressure makes welding arc unstable and the presence of diffusible hydrogen and brittle microstructures in the welds can be the reasons of cracks formation. In the most cases underwater welding is used for joining carbon steels, low alloy steels austenitic and duplex stainless steels. Weldability of steel in water environment is governed by its cold or hot cracking tendency. Susceptibility to cold cracking is main problem in welding of high strength low alloy steels (HSLA) and fabrication of dissimilar joints. Hot cracks in the most cases are observed in weld metal of fully austenitic stainless steels.

Unfavorable structure transformations in HAZ can be avoided by controlling of cooling rate of welded joint by the use of special insulation on surface of the welded plate and apply high heat inputs. Welding practices that reduce residual stresses in the joints include: the use of small weld deposits and consumables with compatible coefficients of thermal expansion with base material and the selection of edge preparations which reduce weld deposit. The strength of the steel used for the deep-water structures is very important factor, because high strength steel (yield strength over $350 \mathrm{MPa}$ ) is required at greater depths. High strength steels usually have carbon equivalents greater than $0.4 \%$ and show worse weldability. 


\section{Conclusion}

Modern techniques of underwater welding give possibility of obtaining joints with sound welds that meets requirements of classification societies. Recent improvements in underwater welding have led to the increased use of wet and dry hyperbaric welding for marine applications. But more spread application of wet welding methods is limited due to common opinion of low quality of welds performed by this method. The general acceptance of underwater welding processes has been further advanced by the standardization of methods, procedures, and certification requirements provided by the American National Standards Institute and American Welding Society. In spite of many successful applications and results of investigations, underwater welding requires new research and development to achieve its full potential.

Hardness values in this region approach $600 \mathrm{Hk}(100 \mathrm{~g})$ although the extent of this zone is less than $0.5 \mathrm{~mm}$. The HAZ hardening in underwater welding is not totally beyond control, since higher heat inputs associated with the larger 3/16 in electrode did produce less hardening. The weld bead shape of underwater and air welds was found to be very similar at the same welding current and speed. The similarity of the weld bead shape along with the almost identical volt-ampere recordings suggest that the primary effect of the water medium is to produce very rapid solidification and cooling once the weld puddle has been formed, and that the water does not have a major effect on the penetration or other aspects of the weld puddle formation.

\section{References}

[1]. Book Km. Moeed Manufacturing-2

[2]. https://www.google.co.in/url?sa=i\&rct=i\&q=\&esrc=s\&source=images\&cd=\&cad=rja\&uact=8\&ved=0ahUKEwiOmuus4qLPAhXI ZQKHVheBkQQjRwIBw\&url=http\%3A\%2F\%2Fwww.welderreferer.com\%2F2015\%2F08\%2Fthe-underwater-welding-process.ht ml\&psig=AFQjCNGJ0KCa9Sxm9v6D4ZjFzrKRWtwV5Q\&ust=1474626605766090

[3]. $\quad$ https://www.google.co.in/url?sa=i\&rct=j\&q=\&esrc=s\&source=images\&cd=\&cad=rja \&uact=8\&ved=0ahUKEwj-wYa24qLPAhXK p5QKHYGGCecQjRwIBw\&url=http\%3A\%2F\%2Fwww.welding-advisers.com\%2FPreview2.html\&psig=AFQjCNGJ0KCa9Sxm9 v6D4ZjFzrKRWtwV5Q\&ust $=1474626605766090$

[4]. $\quad$ https://www.google.co.in/search?q=underwater+welding+process\&source=lnms\&tbm=isch\&sa=X\&ved=0ahUKEwjVk66n4qLPA hUJ32MKHf4-C2EQ_AUICSgCl 